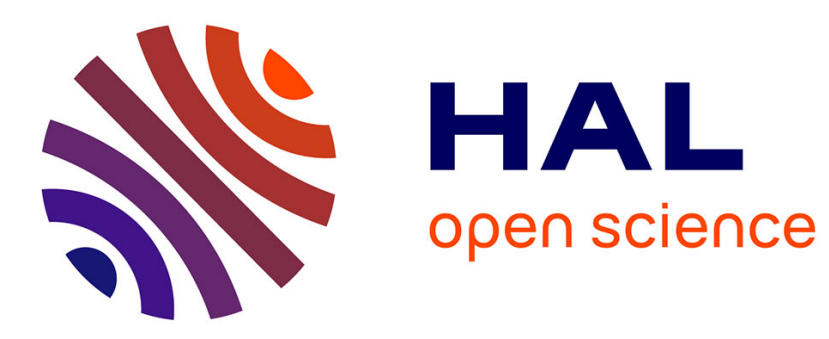

\title{
Events are perceived earlier in peripheral vision
}

\author{
Ljubica Jovanovic, Pascal Mamassian
}

\section{To cite this version:}

Ljubica Jovanovic, Pascal Mamassian. Events are perceived earlier in peripheral vision. Current Biology - CB, 2020, 30 (21), pp.R1299-R1300. 10.1016/j.cub.2020.08.096 . hal-03049344

\section{HAL Id: hal-03049344 \\ https://cnrs.hal.science/hal-03049344}

Submitted on 9 Dec 2020

HAL is a multi-disciplinary open access archive for the deposit and dissemination of scientific research documents, whether they are published or not. The documents may come from teaching and research institutions in France or abroad, or from public or private research centers.
L'archive ouverte pluridisciplinaire HAL, est destinée au dépôt et à la diffusion de documents scientifiques de niveau recherche, publiés ou non, émanant des établissements d'enseignement et de recherche français ou étrangers, des laboratoires publics ou privés. 


\title{
Events are perceived earlier in peripheral vision
}

\author{
Ljubica Jovanovic ${ }^{1,2}$ and Pascal Mamassian ${ }^{1}$
}

1. Laboratoire des systèmes perceptifs, Département d'études cognitives, École normale supérieure, PSL University, CNRS, 75005 Paris, France

2. Neuropsychologie Cognitive, Physiopathologie de la Schizophrénie, Inserm UR 1114, University of Strasbourg, France

Visual perception is not instantaneous. It takes a few milliseconds for light to be transduced in photoreceptors and tens of milliseconds more for neuronal spikes to occur at successive levels of the visual hierarchy. Moreover, the latency of responses varies across the visual field and the cortical hierarchy. In peripheral compared to central vision, the impulse response of primates' ganglion cells has a higher peak occurring at shorter latency (1), and yet humans' primary visual cortex is activated later (2). The diversity of these physiological results makes it difficult to predict when is the perceived present (3), especially when events are perceived across the visual field. This question cannot be directly addressed with paradigms traditionally used to investigate perceptual latencies. In particular, response times are not suitable because they are influenced by decisional mechanisms, motor-related processing or compensatory mechanisms $(4,5)$. Likewise, temporal order judgements between foveal and peripheral stimuli are not suitable because humans overweigh foveal information when making perceptual decisions (6). Here we explicitly asked participants to estimate when a stimulus is perceived within a fixed duration temporal interval, rather than relative to another stimulus presented in its near temporal proximity. We show that the perceived time of a visual event depends on its position in the visual field. We find a large bias to report events earlier when they were presented in the periphery.

Participants first learned the duration of a fixed interval that was used as a temporal frame in the main part of the experiment. A bar representing the hand of a clock (Figure 1A) 
made a full revolution in 2 seconds. In the main part of the experiment (Figure $2 \mathrm{~B}$ ), the hand of the clock was no longer presented, and participants were asked to attend to the whole duration of the temporal frame. The start and end of the frame were signalled by a change of the fixation point and a brief tone. On each trial, at random times after the frame onset, a pair of clearly visible stimuli were presented briefly (33 ms) on either side of the fixation. At the frame offset, the hand of the clock was presented, and participants adjusted its position to indicate when the event was perceived. 

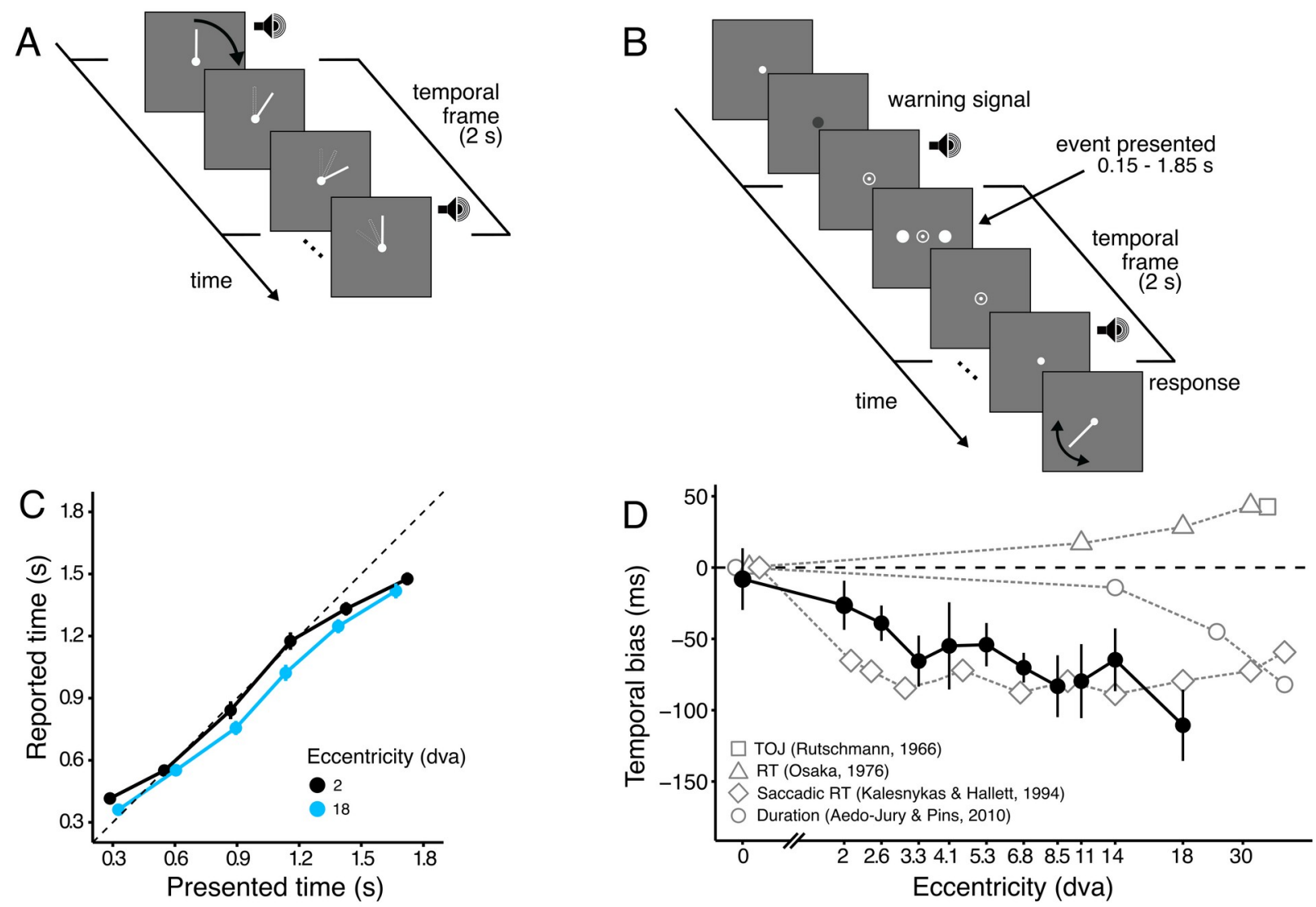

Figure 1. Perceived time of visual events depends on their position in the visual field.

(A) Familiarization with temporal frame duration. At the beginning of the experiment, participants were presented with the hand of a clock rotating at a constant velocity over 2 seconds for one full revolution. A brief $1 \mathrm{kHz}$ pure tone was presented at the beginning and at the end of the full revolution, as an additional cue to facilitate learning of the frame duration. (B) Illustration of the stimulus sequence. During the temporal frame in the experiment, the hand of the clock was not presented. At the start of the temporal frame, the fixation disc changed to a small dot, and a brief tone was presented. After a random delay, an event consisting of two dots on either side of the fixation were simultaneously presented. The temporal frame ended after 2 seconds, and it was marked by a change of the point of fixation and a brief tone. Participants moved the mouse cursor to place the hand in the position where it would have been at the time the event was presented. (C) Reported time against presented time for different eccentricities (colour coded). Presented time was quantized in six equal sized bins, and reported time was averaged across bins and participants. There is a shift in the reported time for larger eccentricities (blue relative to black symbols). For clarity, only the two extreme eccentricities (2 and $18 \mathrm{dva}$ ) are shown. (D) Average temporal bias across tested eccentricities (black symbols). The events presented in the periphery were reported earlier than events presented at the fovea, with the bias increasing with eccentricity. The bias is averaged across participants $(\mathrm{N}=8)$, and error bars correspond to standard error of the mean between participants. Results from previous work investigating temporal biases across the visual field are shown in grey symbols for comparison. For comparison with our data, all values are normalised relative to the foveal presentation.

We tested the perceived time for events presented at fixation and ten different eccentricities (from 2 to 18 degrees of visual angle). Events presented at fixation were perceived veridically, but there was a large bias to report events earlier (negative temporal bias) when they were presented in the periphery (Figure 1D). From a trial-by-trial linear 
mixed-effect analysis, we found that temporal bias (the difference between reported and presented time) was affected by the position of the event in the visual field $\left(X^{2}(1)=23.65\right.$, $p<0.001)$. We also found that temporal bias was affected by presented time $\left(\chi^{2}(1)=679.5\right.$, $p<0.001$ ), showing the presence of a range effect. Importantly, there was no interaction between presented time and eccentricity, indicating a constant range effect irrespective the eccentricity $\left(\chi^{2}(1)=0.45, p=0.5\right.$; Figures $1 C$ and $\left.1 D\right)$.

Our findings are at odds with previous investigations of the perceived synchrony between centrally and peripherally presented stimuli. In one classical study in particular (7), a peripheral stimulus needed to be presented earlier for it to be perceived simultaneous with a foveal stimulus. However, given the temporal uncertainty of the first stimulus in these experiments, and known biases favouring centrally presented stimuli (6), it is plausible that these previous results were confounded by the time needed to shift attention to a peripheral location.

When attention is diffused across a large area of space, temporal resolution is impaired (8). It is important to remember that there was no spatial uncertainty about the location of the event in our experiment. Therefore, the absence of interaction between presented time and eccentricity suggests that the temporal bias in favour of peripheral events is not due to attention.

When the present is perceived is an important and not well understood problem. The most straightforward hypothesis is that the perceived time of a stimulus is related to its processing, and that events are perceived when processing of some aspect of the stimulus is completed. Nevertheless, it is not clear which aspect of stimulus processing could be used as a timestamp. Our results show that perceived time is not just a readout of the first cortical response to the onset of the stimulus, which is known to be later for stimuli presented peripherally (2) and thus opposite to our results. An early response in periphery would be consistent with a peripheral clock running slower than a central one. However, this explanation would imply an interaction between presented time and eccentricity, and we found no evidence for this interaction (see also Supplementary Material for another 
failed prediction from this clock-based explanation). Instead, perceived time seems better correlated with the speed of processing of visual information, which is faster in the periphery for discrimination tasks (4). Faster processing in the periphery could lead to reporting events earlier at those locations if the perceived time of the stimulus corresponds to the time when processing is completed. Alternatively, salient features from early responses to stimuli could be used as markers to encode event time $(9,5)$. Transient responses of peripherally presented visual stimuli (1) could make them more salient, and therefore reported earlier than centrally presented stimuli.

We have shown that there is a difference in the perceived time between central and peripheral stimuli by as much as $100 \mathrm{~ms}$. Given the magnitude of the effect, it is surprising that these asynchronies are not noticed in everyday life. This suggests that our visual system has learned to ignore these differences, or to compensate for them. A possible compensation mechanism could involve contingencies in appearance between peripherally and centrally presented stimuli before and after a saccadic eye-movement (10). 


\section{References}

[1] Solomon, S. G., Martin, P. R., White, A. J., Rüttiger, L., and Lee, B. B. (2002). Modulation sensitivity of ganglion cells in peripheral retina of macaque. Vis. Res. 42, 2893-2898.

[2] Zhou, B., Bao, Y., Sander, T., Trahms, L., and Pöppel, E. (2010). Dissociation of summation and peak latencies in visual processing: An MEG study on stimulus eccentricity. Neurosci. Lett. 483, 101-104.

[3] Fraisse, P. (1984). Perception and estimation of time. Annu. Rev. Psychol. 35, 1-36.

[4] Carrasco, M., McElree, B., Denisova, K., and Giordano, A. M. (2003). Speed of visual processing increases with eccentricity. Nat. Neurosci. 6, 699.

[5] Adams, W. J., \& Mamassian, P. (2004). The effects of task and saliency on latencies for colour and motion processing. Proc. R. Soc. Lond. B 271, 139-146.

[6] Gloriani, A. H., \& Schütz, A. C. (2019). Humans trust central vision more than peripheral vision even in the dark. Curr. Biol. 29, 1206-1210.

[7] Rutschmann, R. (1966). Perception of temporal order and relative visual latency. Science 152, 1099-1101.

[8] Poggel, D. A., Treutwein, B., Calmanti, C., and Strasburger, H. (2006). Increasing the temporal $g(r) a i n:$ Double-pulse resolution is affected by the size of the attention focus. Vis. Res. 46, 29983008.

[9] Nishida, S. Y., \& Johnston, A. (2002). Marker correspondence, not processing latency, determines temporal binding of visual attributes. Curr. Biol. 12, 359-368.

[10] Valsecchi, M. \& Gegenfurtner, K. (2016). Dynamic re-calibration of perceived size in fovea and periphery through predictable size changes. Curr. Biol. 26, 59-63. 